\title{
The Electronic Payment Systems in a Developing Economy with Reference to Guyana
}

\author{
Imran Khan \\ Ph.D. in Strategic Management, Texila American University, Guyana
}

\begin{abstract}
The general intention of this Publication is to feature Electronic Payment Systems in a Developing Economy with reference to Guyana and the bearing comprising the advantages in cultivating payment systems while heightening safety, the efficiency of payments, and cost savings. The continuous transformation of a developing economy's payments system will support monetary growth through the fiscal system for its sustainability and enables proficient financial interposition. This publication further highlights the need for frequent evaluation and supervision for the continuous modernization of electronic payment systems to the benefit and referencing to the developing economy of Guyana. Critical areas that are essential which emphasis have been placed upon but needs further attention in addressing, are as follows:

1. Increase the rate of finalizing a transaction through its related operations within actual or rapid time, as time is money. Currently, the rate of one transaction varies (by hours).

2. Decrease of paper materials and handling costs which generally eases functional cost.

3. Payment assurance and dependable guard against illegal entry to the client's account in ensuring safe dispensation.

This publication has formed the basis to associate investors behind the target to endorse a modern payments system infrastructure that is required for a developing economy with reference to Guyana with the objective of restructuring, empowering discussion and the propelling effect in generating inventive and country-specific electronic payment solutions. It should be noted that a substantial amount of transformation has occurred to date with reference to Guyana.
\end{abstract}

Keywords: Developing Economy, Electronic Payment Systems, Implementation.

\section{Introduction}

Electronic Payment Systems (EPS) development generally has been described as difficult and unnatural with varied challenges in developing countries which has socioeconomic surroundings similar to Guyana in many ways. EPS development, in particular, is faced with trials fluctuating from lack of acceptable lawful backing, power issues, reliability of the human element and deficiency of expert resources, the veracity of data transmitted, absence of infrastructures, interconnectivity, and interoperability, attributable to the country's hitech infrastructure and institutional aptitude.
Many years of progress aid have botched to bring the anticipated results of advancement in most developing countries, partially due to the emphasis on largescale methods and procedures which do not focus on the local organized context faced by money-making agents in those progressing countries. This makes getting the right organized context a key issue for most progressing countries particularly for the development of information systems of electronic payments which are entrenched and much manipulated by the established setting.

Payment systems progression, like every IT growing characteristic, is seen as both public and 
political processes, shaped by governmental and socially created realities of its settings. EPS development therefore may have to take into consideration a whole range of factors, particularly the state of development of the socio-political set up in the country which is usually regarded as poorly developed in growing countries.

The range of factors to consider includes system of actors involved, their connections and effects, and how they are subjective by the organized settings. Another critical factor is the procedures and fundamentals that make up the payment systems which include the payment framework, lawful framework, and official provisions, and how they individually and cooperatively impact growth and advancement.

EPS is an inter-organizational information system that transcends structural boundaries, thus the cooperation of the stakeholders and allocation of resources and how it interrelates and impacts the essential of the payments system may also be key issues in the growth of EPS. Although technology serves as the mainstay driver of EPS, administrative and cooperative issues that shield working arrangements/relationships, authority, procedures, economic, social, trust issues, etc., are other significant issues to be taken into thought for the development of any EPS. Regrettably, EPS growth is often too barely focused on tools, expertise, and structure which progressing countries have encounters with, referenced to Guyana. This has not yielded expected results, particularly in most progressing countries where the other fundamentals of payment systems are poorly established and as such fail to give appropriate support to the payment system framework and gives way to gradual advancement and confidence of the EPS.

A payments system infrastructure requires supplementary institutional arrangements supported by a sufficient legal framework to promote sturdiness. The inducements to advance overall payment system efficacy have been troubled by the recurrent effect of risk shifting due to the uncompensated and unintentional fluctuating of credit and liquidity risks through payment instruments and allied institutions. This covertly challenges the legal, operational and governance fundamentals of the payment system which are organizational, country-specific and signify key facets of the process of payment systems progression. These encounters may have contributed to the unequal accomplishment of comparable restructuring in different countries and resulted in a design-actuality gap that has made the success of planned outcomes difficult in terms of anticipated use, benefits, and costs. The essentials of these institutional features may have to be considered to fix the most applicable mix and suitable improvement approach of the respective developing economy.

This publication is to highlight and substantiate that a developing economy with reference to Guyana has evolved in building a robust, safe, sound, efficient, and inclusive EPS that meets the current and future needs of the country over time. Further, it has and will continue to support monetary activity and financial sector development, advances the use of electronic payments, assists with financial risk mitigation, achieves compatibility with international systems, adheres to the applicable international principles, procedures, and codes. In achieving these, the following gratifications are projected based on data and research approach to be realized in the evolution process:

1. Performing a comprehensive legal \& regulatory framework.

2. Boost the efficiency of electronic payments processing and decrease resolution times for both retail and large value transactions.

3. Entice higher rates of electronic payments, approval by vendors, merchants and other providers of goods and services.

4. Reinforce risk management mitigation across the developing economy's payment system infrastructure.

5. Fortify oversight framework and capability of the respective Central Bank. 
6. Increase availability of electronic payment access networks and support e-commerce.

7. Maximum use of available liquidity in terms of financial resources is made.

8. Participating in payment and settlement infrastructures is on a fair and equal basis.

9. Encouraging healthy competition amongst Payments Service Providers (PSP).

10. Delivery versus payment (DvP) for securities transactions is succeeded and maintained.

11. Payment versus payment (PvP) for foreign exchange transactions is completed and sustained.

12. Internationally compatibility is recognized and upheld.

13. Cost efficacy is realized and sustained.

14. Openness is wide-ranging based and farreaching throughout the growing economy.

15. Treats are identified, mitigated, and well managed to ensure no or low impact.

16. Adults accept and use cashless payments dominantly.

17. Acknowledgement of electronic payments by vendors, merchants, and other providers of goods and services increases steadily.

18. Payment services, instruments and access channels are interoperable.

19. Rivalry and revolution are supported by level playing fields and equitable access for PSPs to the use of payments system infrastructures.

20. Transmittal service costs fall in line with the regional or global average.

21. Greater use is made of authorized remittance services.

22. Government agencies and quasigovernment entities reduce their use of cash.

23. Irrevocability of settled transactions.

24. Shield of funds.

25. Risk control measures are state of the art.

26. Effective customer complaint \& dispute resolution.

27. Effective fraud prevention and detection measures.

28. Data confidentiality and security.
29. Adherence to national rules

30. Imran - Regulations, and procedures.

31. Achievement of delivery vs. payment.

\section{Growth of Electronic Payment Systems (EPS) Overtime}

Clearing in banking indicates the transfer of funds from one person to another. This clearing of the fund can take place in two (2) ways either through cash or through cheque in cash-oriented societies. There has been no significant change in the cash transactions except for the changes in the value of money in developing countries. However, the cheque clearing system has undergone a lot of changes over time with movement to Electronic Cheque Clearing instead of the manual method.

The origin of a cheque can be traced back to the first century $\mathrm{AD}$, where banks used to issue letters of credit wherein the banks used to pay the identified payees as per the instructions. This eradicated the burdensome process of carrying money or previous metals (gold, etc.) which were very risky. Changes have taken place in cheque clearing over the period of time from ordinary cheque clearing to MICR clearing and finally to the latest in clearing 'Cheque Truncation System'. This publication paper sightsees the changes that have taken place in the bank clearing system in the past, present and will also try to picture the future of bank clearing which integrates the electronic payments system in a developing economy with reference to Guyana.

It can be considered that the progression of cashless payments is a result of a new idea to simplify the way of payments, which was then slowly embraced in peoples' life. These days, the payments business is a decisive source of income and figures and a desperate for broader customer relationships. The payment industry continues to progress and offer new creativities to their customers [1].

The World Payment Report [2-4] highlights the critical findings of worldwide non-cash transactions during the last decade and is the 
leading supplier for data, trends of e-payments, and main industry and supervisory initiatives. According to this source, the global non-cash payments can be characterized as a fast-growing market, especially in the emerging markets: emerging Asia, with a growth rate of $43.4 \%$, and Central Europe, the Middle East, and Africa (CEMEA), with a growth of $16.4 \%$ (2014-15 data). While the total non-cash transaction volumes grew $11.2 \%$ during 2014-2015 and reached 433.1 billion, the rate of progression in Europe changed from $7.3 \%$ to $7.5 \%$. Perceptible growth was shown in the following countries: Germany, Spain, Finland, Ireland, Sweden, and Denmark. It should be noted that China is in third place with 38.1 billion transactions (63.2\% growth rate).

Electronic payment transaction technological expertise is associated encouragingly to actual economic collections. This has been more obvious with the Euro economy countries. The findings of the European Central Bank Working paper 'Retail Payments and the Real Economy' [5] provided deep analyses of 27 European Member States over the period 1995-2009 and proved 7 main hypotheses, among which, the following may be mentioned: Efficient non-cash retail payment instruments accelerate monetary growth; Cheque payments exercise a lower contribution on GDP, utilization and commerce in contrast to other non-cash payment instruments; The optimistic impact of credit transfers on actual economic development is greater in the euro area countries than in the noneuro area countries; The acceptance of new payment technologies results in supplementary economic progression. The different means of non-cash payments are growing around the world. Modernisms are more relaxing to use for young people. For example, emerging Asian markets are driving to accelerate e-commerce progression. Despite this, 'E-Payments in Emerging Markets [6, 7] states that many countryside areas still do not have banking systems, while those that do are slowly moving from cash to electronic payments similar to what is existing in Guyana.

It was further highlighted the role of government in the investment in new technologies, managing e-instrument security, enhancing financial inclusion, and leveraging existing market players. What will be the next stage: it's clear that the future is bright and that opportunities abound with carefully planned strategies and reliable partners [6, 7], EPayments in Emerging Markets, A First Data White Paper, Journal of Payments Strategy and Systems, Volume 7, Number 4). The specific area of e-payments is electronic business, which created new opportunities for sending and receiving of payment instructions. The paper [8] E-payments in Europe - The Euro system's Perspective investigates the fresh approaches and techniques, which developed to adopt outdated payment instruments for use in the internet: credit cards, credit transfers, and debit instruments.

The development of e-business helped to raise a new type of payment service providers and advance new types of electronic instruments such as prepaid cards, electronic wallets, and others together with the security issues of those instruments. The main conclusion is that the Euro system endeavors, in co-operation with standardization bodies and market participants, to help strike the right balance between competing and commonly agreed standards. Another in-depth survey on the development of electronic money and internet and mobile payments was published by the Bank of International Settlement (BIS) updated Survey, which included the information collected from 95 countries around the world. The focus of this survey was not technical purposes, but the market impact of innovations. Based on the information and data provided by the Survey respondents from the individual country, comparative tables on the use of innovative products and systems were designed. In the survey, the data was collected in end-2002 or 
2003, and covered schemes that were being considered, piloted or implemented [9].

The acceptance of the new means of cashless payments has had a significant effect on developing economies with reference to Guyana. This was proved by the study Cashless payment and economic growth [10]. Specifically, the impact of cards, telegraphic transfers, electronic money, and cheques on the economies of Australia, Belgium, France, Germany. and Portugal for the period of 2000-2012.

The research was piloted by the use of Pedroni's outstanding integration and the Panel Course Error Correction Model. The main message stated from this report is that the acceptance of one type of cashless payment will affect another type of cashless payment in the short run, the consequences of accepting cashless payment on economic development can only be significantly observed in the long run. Hence, any policy that promotes cashless payment will not affect the economy immediately but on a long-term basis.

A payment card is the most popular non-cash payment instrument in the world. It allows consumers to retrieve its funds in the bank which has evolved with reference to Guyana over time and has been used widely of recent especially in the COVOID-19 Pandemic. Increased card usage in the world gives rise to the main question: what kind of benefits it brings to the country. The answer to this question could be found in Moody's Analytics, which offers unique tools and best practices for calculating and overseeing risk through proficiency and know-how credit analysis, business research, and financial risk management. Moody analytics [11] conducted two different research on the encouragement of payment card transactions on the country with the initiative of Visa International. In the first research conducted in 2013, the data of 56 countries was [11] analyzed for the period of 2008-2012 and was stated that the use of credit and debit cards added 983 billion US dollars to the GDP of these 56 Countries.
A similar analysis was conducted in 2016 for the data of 70 countries for card transactions in the period of 2011-2015. According to this research, payment cards usage added 296 billion US dollars to GDP, which means 2.6 million new jobs on average in each year. The main message was stated 'Card usage makes the country more efficient, yielding a meaningful boost to country growth, year after year, through a collection of factors including transaction efficiencies, consumer access to credit and consumer confidence in the payments system overall' [12]. The effect of Debit and credit card transactions together with cheque transactions on GDP was also calculated by [13] 'Statistics Paper Series' of European Central Bank 'Nowcasting GDP with electronic payments data'.

Many Authors have divided the data received from the Canadian Payment association and Bankers' Association for the enquiry in two spans: the first, through the end of 2009. Credit card data were available to them from 2010. The longer data set which extends through April 2012 contained debit and cheque data. In this particular model, with debit card transactions included some enhancement in the correctness of the earliest now casts were found. The outcomes of the study give a big picture of the development in newscasting over time. 'The Analysis of the Factors Influencing on Electronic Payments and Relationship among Azerbaijan's Economy with Them' [14, 15] gives the broad analyses of factors that have a negative influence on the development of cashless payments on Azerbaijan's country as an example. The rise of electronic payments reduced the size of the shadow economy in Azerbaijan correspondingly.

Moreover, unlawful, and small income level, low pension and great utilization, unorganized commerce, infrastructural possibilities and technological level, payment culture and financial literacy, gaps in lawmaking, and other such factors that influence adversely on the growth of cashless payments are analyzed and 
the endorsements have been given in this publication. In addition to these, international experience has been examined in terms of managerial and encouraging guidelines in order to improve cashless payments and endorsements and have been made in this direction with reference to Guyana.

A substantial optimistic relationship between the e-payment system and country development in terms of real GDP per capita and commerce per capita was found in the 'Review of Transition to Cashless Economy in Nigeria' by the authors [17-19]. The main finding is that most of the non-cash payments are provided through bank accounts. With this study, it was highlighted that only Automated Teller Machine (ATM) operations were revealed on economic growth and development something we have seen and keep growing in developing countries with reference to Guyana.

In today's world, economic relations become an integrated part of the culture. The most distinctive such connection in a market country, where the estimation for the condensed services, products, etc. Such estimations can take both cash and cashless form. The form of cash payments is typical for countries with less developed countries with reference to Guyana. In the more developed countries, the transition to non-cash was evident because of a number of compensations. Many countries have both forms of cash payments. Their number may vary depending on the development in the country of science, technology, education, social sphere, etc. if considered that the form of payments in terms of compensations and difficulties, the noncash form is more beneficial in terms of costs, speed, and other costs than cash. Non-cash payments are payments (payments) made without the use of cash, through the movement of funds to accounts with credit organizations and offsets of joint entitlements.

The adequate e-transactions guideline can be used as a mechanism for development. If we talk about developed countries like USA and the EU, cashless payments are $93 \%$ and $91 \%$ respectively. The remunerations provided by epayments are quick access to monetary markets, immediately transactions between entities everywhere in the world, the increase in financial activity, and most important - they are one of the items to support further country growth [20].

The guideline consequence and support of this publication is the comprehension of why effectual EPS development is challenging in certain organizational perspectives. This consideration could help in constructing the mandatory organizational competence and monetary environment that enhances the effective progression of payment systems in a developing country with reference to Guyana. The input for the educational society is an enhanced perception of the impact and interactions of the rudiments of the payment system in the effective growth of payment systems in Guyana. It also features the remunerations of inserting business principles combined with institutional theory in the progression of information systems, such as EPS which is interwoven with monetary and financial interests of relevant stakeholders. For practitioners, the support may be a guide that helps in building organizational aptitude and a surrounding conducive for effective payment systems progression and growth. Thus, the paper reveals a correlation between e-payment increasing and GDP growth. It was researched how the digital nature of money influences the financial system at a whole.

Besides, uploaded dimension of credit-digital nature of money is given. The usage of cashless payment is closely related to the level of economic development. On the one hand, a higher level of well-being and development of the financial system in richer countries encourages cashless transactions. On the other hand, cashless payments contribute to accelerating economic development: through the spreading of electronic payments that can cause consumption growing. The adequate e- 
transactions regulation can be used as an instrument for growing.

The paper describes the latest trends in IT development and its influence on financial sector (especially cashless payment) the global economy faced. So, South Korea, Sweden, Iceland are leading countries. In the cause of Ukraine, there is a positive IT dynamic. If we talk about the USA and EU, cashless payments are $93 \%$ and $91 \%$ respectively. The benefits provided by e-payments are rapid access to financial markets, immediately transactions between entities everywhere in the world, the increase in financial activity and most important - they are one of the items to support further economic development.

\section{Methodology}

The approach used for the purposes of this research is an inductive one. It began with specific observations, which was used to produce generalized theories and conclusions drawn from the research as outlined in the Reference Section mentioned below. The reason for occupying the inductive approach was that it takes into account the context where research effort is active and most current based on already available data from prior research.

For the purposes of this publication, comprehensive observations with related researched data and information were incorporated along with unstructured and informal interviews which helped with identifying participants' emotions, feelings, and opinions regarding the research subject. The unstructured interviews offered flexibility in terms of the flow of the interview, thereby leaving room for the generation of conclusions that were not initially meant to be derived regarding a research subject.

As far as data collection tools were concerned, the crafting of this publication was built primarily from researched artifact collection of information and data as outlined under the Reference Section below. Further, the research design is Analytical and Exploratory. In an analytical approach, the available literature were critically evaluated with the facts and information related to the research being conducted. In the exploratory approach, tried to explore the new avenues for digitalization, as it is a review paper, the data is confined only to secondary sources and no scope for sampling and research tools application.

\section{Results and Discussion}

This publication highlights the interactions of the institutional arrangement with the technological infrastructures and other elements of the EPS, identifying the critical roles. The development of EPS depends not only on the effectiveness of the technical infrastructures but on building a viable institutional capacity that will provide a suitable environment. This publication further substantiates the institutional arrangements and their suitability in meeting the needs of society, the interest of the stakeholders, and the overall continuous development of EPS concerning Guyana.

This publication's output is the understanding of problems encountered during the policy implication, contribution, and effective EPS development in specific institutional contexts. This understanding could help build the required institutional capacity and an economic environment that enhances the effective development of payment systems in a developing country, such as Guyana. The contribution for the academic community is an improved understanding of the influence and interactions of the elements of the payment systems in the effective development of payment systems in Guyana. It also highlights the benefits of applying economic principles combined with institutional theory in developing information systems, such as EPS, which is intertwined with stakeholders' financial and economic interests. For practitioners, the contribution may be a guide that helps in building institutional capacity and an environment suitable. Thus, the paper reveals a correlation between e-payment increase and GDP growth. It was researching 
how the digital nature of money influences the financial system as a whole. Besides, uploaded dimension of credit-digital nature of money is given. The usage of cashless payment is closely related to the level of economic development. On one hand, a higher level of well-being and development of the financial system in richer countries encourages cashless transactions and on the other hand, cashless payments accelerate economic growth by spreading electronic payments that can cause consumption to grow. Adequate regulation can be used as an instrument for increasing e-transactions.

The paper describes the latest trends in IT development and their influence on the financial sector (especially cashless payment) the global economy faces. So, South Korea, Sweden, Iceland are leading countries in the implementation of EPS. In the case of Ukraine, there is a positive IT dynamic. In USA and EU, cashless payments are $93 \%$ and $91 \%$, respectively. The benefits provided by epayments are rapid access to financial markets, immediate transactions between entities everywhere in the world, the increase in financial activity, and, most importantly, items to support further economic development.

Further, this publication revealed the correlation between e-payment increase and GDP growth. The researcher studied the influence of the digital mode of payment in the financial system as a whole. Besides, the loaded dimension of the credit-digital nature of money is also discussed. The usage of cashless payment is closely related to the level of economic development. On one hand, a higher level of well-being and development of the financial system in richer countries encourages cashless transactions. Further, it is also understood that cashless payments accelerate economic growth by spreading electronic payments that can cause consumption to grow.

\section{Conclusion}

A modern electronic payments system for a developing country referenced Guyana with unassertive payment volumes is apparent. The objective is to undertake a comprehensive study of the cost of cash and other payment instruments customary in Guyana to provide a robust platform for the continuous construction and modernizing of Electronic Payment Systems and reforms. A developing country concerning Guyana is recognized as a cash payment cultured country. With most payments are done primarily by cash and cheques, which increases the risk of consumers walking around with lots of money and the cost-effectiveness of supplying paperbased payment instruments. However, over time this has changed progressively integrated with the deadly COVID-19 Virus Pandemic. The pandemic forced many in Guyana and globally to use electronic payments to avoid or reframing from crowds and long queues (lines).

The progression of EPS will hinge on the efficacy of the ever-changing technological infrastructures and on constructing a feasible organizational facility that will provide an appropriate environment. The New Institutional Economics (NIE) theory will thus empower this publication to emphasize the organizational engagements and appropriateness in meeting society's needs. It also meets the interest of the stakeholders and the overall growth of EPS.

A well-developed and efficient payment system is critical for a country's growth and financial stability. By virtue, Guyana undertakes an all-inclusive and strategic restructuring. The transformation of its developing payments system will enhance the use of electronic payments by its stakeholders and the country as a whole over time. Non-cash payments are of great economic significance in fast-tracking the trade of funds, reducing the cash needed for circulation, and reducing circulation costs. A network of commercial banks aids the extensive use of non-cash payments (they are six in Guyana presently). The state's interest in their development, both for the above reason and to examine and control macroeconomic processes that have evolved in Guyana over time. With continuous modernization and reforms, 
Guyana's payments system is in the quest to move away from cash payments to electronic payments. It is estimated to save the country approximately US6.5 billion annually and improve its Gross Domestic Product (GDP) significantly and steadily over time. It is established that with focus should be placed on promoting an infrastructure that includes payment systems such as a fully Automated Clearing House (ACH) inclusive of Electronic Funds Transfer (EFT) and Electronic Cheque Clearing ECC), Real-Time Gross Settlement (RTGS), Central Securities Depository (CSD) and Society for Worldwide Interbank Financial Telecommunications (SWIFT) systems. The focus will realize and benefit Guyana extensively over time as a developing economy in the Western Hemisphere.

\section{References}

[1] Jumba, J., \& Wepukhulu, J. M. (2019). Effect of Cashless Payments on the Financial Performance of Supermarkets in Nairobi County,Kenya. International Journal of Academic Research Business and Social Sciences, 9(3), 1372-1397.

[2] World Bank Payments Report 2017, https://worldpaymentsreport.com/resources/worldpayments-report-

2017/\&ved=2ahUKEwjujrye7qn0AhU5SjABHRZ2 C98QFnoECAoQAg\&usg=AOvVaw185X540z3hX n8CV6t4uzav.

[3] Demirgüç-Kunt, A., \& Klapper, L. F. (2012). Measuring financial inclusion: The global findex database. World bank policy research working paper, (6025).

[4] Cirasino, M., \& García, J. A. (2008). Measuring payment system development. World Bank, Washington, DC.

[5] European Central Bank Working paper 'Retail Payments and the Real Economy' (August 2013), https\%3A\%2F\%2Fwww.ecb.europa.eu\%2Fpub\%2F pdf\%2Fscpwps\%2Fecbwp1572.pdf\&usg=AOvVaw ogjQun3GFdUGsuRKr4UbTm.

\section{Acknowledgement}

This publication is prepared as part and requirement of my $\mathrm{PhD}$ program. I am grateful for the support provided by Texila American University inclusive of their sub-entity Texila International Electronic Journal, my guide Dr. Sasirekha A. and co-guide Dr. Santhi N.S.

\section{Conflict of Interest}

Due to the methods used for this publication, there were no significant conflict (s) of interest encountered as the information gathered from sources was mentioned with and kept with confidentiality with usage solely for the purpose of this publication.

[6] Amrish Rau (2013). E-payments in emerging markets, Journal of Payments Strategy \& Systems, 7(4), 337-343.

[7] Amrish Rau [2013], E-Payments in Emerging Markets, A First Data White Paper, Journal of Payments Strategy and Systems, Volume 7, Number 4).

[8] E-payments in Europe - The Euro system's Perspective (16 September 2002), https://www.ecb.europa.eu/pub/conferences/shared/ pdf/epayments.pdf\&ved=2ahUKEwizgcbu86n0Ah WEaDABHbbaC-

AQFnoECAEQAg\&usg=AOvVaw1gqZonfPqcGgS w9y1AEfdz.

[9] Survey of developments in electronic money and internet and mobile payments [March 2004], Bank for International Settlements, https://www.bis.org/cpmi/publ/d62.htm\&ved=2ahU KEwjKlqXN9Kn0AhXsSjABHVWNBikQFnoECA cQAg\&usg=AOvVaw3F1XIfeeQf7FzJ2cK7ZcyUl. [10] Tee, H. H., \& Ong, H. B. (2016). Cashless payment and economic growth. Financial innovation, 2(1), 1-9. https://doi.org/10.1186/s40854-016-0023$\mathrm{z}$.

[11] Moody analytics analyzed for the period of 2008-2012, https://usa.visa.com/visa- 
everywhere/global-impact/moodys-analytics-studythe-global-impact-of-electronic-

payments.html\&ved=2ahUKEwjEyfWV96n0AhVlT

TABHdArAmgQFnoECAcQAg\&usg=AOvVaw2Bs wwaNPC6uXsXFicS2mkx.

[12]Zandi, M., Singh, V., \& Irving, J. (2013). The impact of electronic payments on economic growth. Moody's Analytics: Economic and Consumer Credit Analytics, 217(2).

[13] Galbraith, J. W., \& Tkacz, G. (2015). Nowcasting GDP with electronic payments data (No. 10). ECB Statistics Paper.

[14] The Analysis of the Factors Influencing on Electronic Payments and Relationship among Azerbaijan's Economy with Them' (2016), https://smartlib.umri.ac.id/assets/uploads/files/d382d -a0706020110.pdf\&ved=2ahUKEwjYypvFan0AhVmQzABHQt_D_kQFnoECAAQAg\&usg=A OvVaw05YwWetukE2zigJtF8mZri.

[15] Taghiyev, K., Eminov, S. I., \& Guliyev, S. R. (2016). The analysis of the factors influencing on electronic payments and relationship among Azerbaijan's economy with them. IOSR Journal of Economics and Finance (IOSR-JEF), 7(6), 01-10.

[16] Taghiyev, K. R., Eminov, S. I., \& Guliyev, S. R. (2016). The impact of cashless payments on economic growth in Azerbaijan. International Journal of Research in Social Sciences, 6(12), 296310 .

[17] Oyewole, O. S., Gambo, J., Abba, M., \& Onuh, M. E. (2013). Electronic payment system and economic growth: a review of transition to cashless economy in Nigeria. International Journal of Scientific Engineering and Technology, 2(9), 913918.

[18] Akhalumeh, P. B., \& Ohiokha, F. (2012). Nigeria's cashless economy: The imperatives. International Journal of Management and Business Studies, 2(2), 31-36.

[19] Mieseigha, E. G., \& Ogbodo, U. K. (2013). An empirical analysis of the benefits of cashless economy on Nigeria's economic development. Research Journal of Finance and Accounting, 4(17), 11-16.

[20] Slozko, O., Pelo, A. (2014), The Electronic Payments as a Major Factor for Further Economic Development, Economics and Sociology, Vol. 7, No 3 , pp. 130-140, https://www.economicssociology.eu/files/14_44_Slozko_Pelo.pdf. 